

\title{
Factors associated with antibiotic prescription among healthcare workers at tertiary hospitals in Nairobi County, Kenya
}

Mbuthia OW*1, Ndonga EN1, Odiwuor SO2, Muraguri MW1

${ }^{1}$ Department of Epidemiology and Biostatistics, School of Public Health, Mount Kenya University, Thika, P.

O. Box 342 - 001000, Thika, Kenya.

2Department of Biochemistry and Biotechnology, School of Pure and Applied Sciences, Pwani University, Kilifi, Kenya.

*Correspondence: Dr OW Mbuthia, Department of Epidemiology and Biostatistics, School of Public Health, Mount Kenya University, Thika, P. O. Box 342 - 001000, Thika, Kenya. Email: oliver.mbuthia@gmail.com;

ORCID - https://orcid.org/0000-0002-3030-8546.

\begin{abstract}
Background: Globally, there has been an overall decline in the effectiveness of antibiotics resulting in an upsurge in bacterial resistance, increased cost of healthcare and consequent high morbidity and mortality rates.

Objective: To determine antibiotic prescription practices among healthcare workers at the Kenyatta National Hospital, Mbagathi, Pumwani Maternity and Mama Lucy Kibaki Hospitals, Nairobi, Kenya.

Methods: The study design was a mixture of quantitative and qualitative methods. Self-administered questionnaires were used to gather information from 230 prescribing healthcare workers. Interviews and Focus Group Discussions (FGDs) were conducted purposively with the prescribing healthcare workers and patients to obtain qualitative data.

Results: There was a significant difference in the distribution of study participants with regards to the availability of antibiotics prescribing policy $(\mathrm{p}=0.05)$. Only $53(23 \%)$ prescribers prescribed antibiotics as per the policy guide while 51 (22.2\%) did not and 126 (54.8\%) were not sure. Oral antibiotics (OR = 0.5, 95\%CI 0.3-0.9), always referring to the 2016 Kenya Essential Medicines List (KEML) to prescribe antibiotics (OR $=4.2,95 \%$ CI 1.3 13.1), separating antibiograms for inpatient and outpatient departments ( $\mathrm{OR}=4.3,95 \% \mathrm{CI} 1.11-15.5)$, and confidence of healthcare workers to prescribe antibiotics without laboratory tests (OR $=0.3,95 \% \mathrm{CI} 0.2-0.8)$ were associated with the prescription of antibiotics.

Conclusion: There is need to improve antibiotic prescription practices among healthcare workers in public tertiary hospitals in Nairobi County to promote rational antibiotic use and control bacterial resistance.
\end{abstract}

Keywords: Antibiograms, Antibiotic prescription, Antibiotic resistance, Kenya Essential Medicines List, Policy.

\section{Introduction}

Antibiotics have contributed significantly to saving human lives from bacterial infections. They remain an important category of medications for general and specialized applications in treating infectious diseases.
However, reports indicate that half of the countries globally fail to implement basic policies to promote rational use of the medications. [1] Reference to a comprehensive review of previous studies that involved 900 studies in 104 countries concluded that $54 \%$ of antibiotics were prescribed in developing 
countries. [2] The World Health Organization (WHO) recommends a global reference range of $20.0 \%-26.8 \%$ prescription rate for antibiotics. [3]

The situation is more important especially in Africa, where data from much recent work has shown that the inclination to readily prescribe antibiotics is worsening. Higher antibiotic prescribing rates have been documented in the period between 2005 and 2015 (49.0\%) compared to the period between 1995 and 2005 (43.1\%). [4] Perhaps this observation may be attributed to the high prevalence of infectious diseases in Africa. Nevertheless, there are situations where the diagnosis is known to be non-bacterial, yet healthcare workers have been documented to prescribe antibiotics. Studies in Africa and other parts of the world have observed that antibiotics were, sometimes, prescribed for malaria, viral and diarrheal diseases despite lacking clinical indications for antibiotic therapy. ${ }^{[5,6]}$ There is now a considerable general consensus that prescription-only antibiotics have been misused and the situation is growing rapidly with possible eventual disastrous consequences.

The development of bacterial resistance to antibiotics has been the most alarming repercussion of irrational prescriptions. [7] Most antibiotics that were previously effective against specific bacterial groups have lost that potential, presenting a current and future threat to public health globally. [1] The first WHO Global Report of 2014 provided the most elaborate revelation on bacterial resistance following an analysis of its 114 member states. [8] Indiscriminately written empirical antibiotic prescriptions by medical practitioners without subjecting isolates to susceptibility tests have considerably aggravated this situation. On the same note, pharmacists who dispense prescription-only antibiotics without healthcare workers' assessment have also contributed to the problem of resistance. ${ }^{[8]}$
In Kenya, a high rate of antibiotic prescription among the healthcare workers has previously been reported but the factors leading to irrational antibiotic prescription remains obscure. [9] In the present study, we explored antibiotic prescription practices among healthcare workers by determining the factors associated with antibiotic prescriptions. The study findings may be useful for policy formulation and implementation of antibiotic prescription strategies among healthcare workers (HCWs). This is likely to reduce the irrational use of antibiotics which is a leading factor for the emergence and spread of bacterial strains that are a public health threat.

\section{Methods}

\section{Study design}

The study design was a mixture of quantitative and qualitative methods. The study targeted prescribing healthcare workers and patients in the four main public tertiary health facilities of Nairobi County, Kenya.

\section{Study site}

The Kenyatta National Hospital, located in Nairobi West, is the largest in East Africa with over 2000 bed capacity and 24 departments. It serves as the country`s teaching, research and referral hospital and caters for a diverse community, both local and international. Mbagathi Hospital which is also located in Nairobi West is adjacent to Kibera slum, the largest slum in Kenya, and serves over 1000 patients per day. Pumwani Maternity Hospital, located in the Northern part of Nairobi County, is the largest maternity referral hospital in Kenya and sub-Saharan Africa. The hospital has 354 obstetric beds, 144 baby cots and two theatres with a total of 50 to 100 normal deliveries and 10-15 Caesarean sections performed daily. [10] Mama Lucy Kibaki Hospital is located within Nairobi East, with a capacity of over 1000 patients on a daily basis. 


\section{Study population}

The quantitative aspect of the study was conducted among prescribing HCWs (clinicians, dentists, pharmacists) both at the inpatient and outpatient departments while the qualitative aspect was conducted among the patients.

\section{Data collection}

The quantitative data were obtained from the self-administered questionnaires administered to prescribing HCWs working in specific units/departments within the hospitals. The qualitative data was obtained from Key Informants (KII) and the participants (patients) in Focus Group Discussions. The Key Informants and FGDs were purposively sampled and formed across the four hospitals. In total, six FGDs were conducted with the patients while 21 face-to-face KIIs comprising of senior prescribing HCWs were also interviewed. Upon reading all the transcripts, 17 interviews provided the specific thematic content of interest related to the study objectives and data saturation was deemed sufficient. The key themes included the antibiotic prescribing policy guide that entailed regional or institutional-based antibiotic prescribing data (antibiograms) and the Kenya Essential Medicines List guide to prescribing antibiotics.

\section{Sample size determination}

With the population of prescribing HCWs of about 450 in Nairobi County public hospitals, the sample size was estimated as described by Daniel [11] with a at 0.05 , and a prevalence of $50 \%$. This yielded a sample size of 230 prescribing HCWs, taking into account 10\% addition to the minimum sample size of 207 to achieve a 0.95 power. To attain the 230 samples, prescribers were randomly selected and issued with questionnaires within the clinical units spread among the four hospitals. Considering the variance in numbers of prescribing healthcare workers serving within each selected health facility, half of the participating prescribing healthcare workers
(115) were recruited from Kenyatta National Hospital, 57 from Mbagathi Hospital, while the rest were recruited equally (29 each) from Mama Lucy Kibaki and Pumwani Maternity Hospitals.

\section{Data analyses}

The data were managed and analyzed using STATA vs. 13 (StataCorp LP, College Station, TX, USA). Descriptive statistics were used to summarize the quantitative data. In bivariate analyses, Odds ratios (OR) and 95\% Confidence Intervals (CI) for the association between prescribing healthcare workers' antibiotics prescription practices and prescription-related factors were determined using logistic regression. The qualitative data (FGD and KII) were subjected to thematic content analysis. This approach entailed the categorization of recurrent data collected under thematic areas. The analysis was done manually using general-purpose software tools using Microsoft Word ${ }^{\circledR}$.

\section{Ethical considerations}

The study was approved by the Mount Kenya University Ethics and Research Review and the joint Kenyatta National Hospital/the University of Nairobi Ethics and Research Review Committees (numbers MKU/ERC/0839 and KNH-ERC/A/16 respectively). Permissions to conduct the research were also obtained from the National Commission for Science Technology and Innovation (number NACOSTI/P/18/15949/23938), the administration of Nairobi County Government and from the respective hospitals.

\section{Results}

Socio-demographic characteristics of the study population

The 230 participants comprised prescribing healthcare workers and hospital administrators who consented and responded to the questionnaire survey. Table I summarizes the demographic characteristics 
of the participants. The mean $( \pm S D)$ age of the participants was $29.2 \pm 5.9$ years with a range of 21 to 51 years. The majority $(152 ; 66.1 \%)$ of the participants were aged between 20 and 30 years while those aged between 41 and 51 years were the least in proportion.

Table I: Socio-demographic parameters of study population $(n=230)$

\begin{tabular}{|c|c|c|}
\hline Variables & Frequency & Percentage \\
\hline \multicolumn{3}{|l|}{ Gender } \\
\hline Male & 117 & 50.9 \\
\hline Female & 113 & 49.1 \\
\hline \multicolumn{3}{|l|}{ Age (Years) } \\
\hline Mean ( \pm SD) & 29.27 & $( \pm 5.916)$ \\
\hline Median (IQR) & 27 & $( \pm 8)$ \\
\hline Range & 30 & $(21-51)$ \\
\hline $20-30$ & 152 & 66.1 \\
\hline $31-40$ & 63 & 27.4 \\
\hline $41-50$ & 15 & 6.5 \\
\hline \multicolumn{3}{|c|}{$\begin{array}{l}\text { Specialized in diagnosis, treatment and } \\
\text { management of infectious diseases }\end{array}$} \\
\hline Yes & 3 & 1.3 \\
\hline No & 227 & 98.7 \\
\hline \multicolumn{3}{|l|}{ Education level } \\
\hline Diploma & 144 & 62.6 \\
\hline Higher diploma & 13 & 5.7 \\
\hline Undergraduate & 56 & 24.3 \\
\hline Postgraduate & 17 & 7.4 \\
\hline \multicolumn{3}{|c|}{ Occupation/ Cadre } \\
\hline Clinical officer & 144 & 62.6 \\
\hline Medical officer & 36 & 15.7 \\
\hline Dentist & 23 & 10 \\
\hline Pharmacist & 27 & 11.7 \\
\hline
\end{tabular}

There were $(117 ; 50.9 \%)$ males and $(113 ; 49.1 \%)$ females. Diploma and Higher Diploma holders accounted for the majority of the participants $(157 ; 68.3 \%)$, followed by bachelor degree holders $(56 ; 24.3 \%)$ while $(17,7.4 \%)$ had postgraduate education. Only three of the participants were specialized in infectious diseases.
Factors associated with antibiotic prescription patterns

Fifty-three (23.0\%) participants prescribed antibiotics according to the prescription policy guide. Prescribers' gender, age, specialization in infectious diseases, level of education and cadre were not associated with prescription of antibiotics according to the antibiotic prescription policy $(p=0.05)$ (Table II). 
Table II: Bivariate analysis of factors associated with antibiotic prescription as per the policy guide

\begin{tabular}{|c|c|c|c|c|c|}
\hline \multirow{3}{*}{ Variables } & \multirow{3}{*}{$\begin{array}{l}\text { Total } \\
(\mathrm{n}=230)\end{array}$} & \multirow{2}{*}{\multicolumn{2}{|c|}{$\begin{array}{l}\text { Prescribed antibiotics as } \\
\text { per the antibiotic policy }\end{array}$}} & \multirow{3}{*}{$P$-value } & \multirow{3}{*}{ uOR $(95 \%$ CI $)$} \\
\hline & & & & & \\
\hline & & $\mathrm{n}=53$ & $\%$ & & \\
\hline \multicolumn{6}{|l|}{ Gender } \\
\hline Male & 117 & 21 & 17.9 & 0.104 & $1.6(0.9-2.7)$ \\
\hline Female & 113 & 32 & 28.3 & Reference & Reference \\
\hline \multicolumn{6}{|l|}{ Age (Years) } \\
\hline $20-30$ & 152 & 37 & 24.3 & 0.743 & $1.2(0.4-3.9)$ \\
\hline $31-40$ & 63 & 13 & 20.6 & 0.961 & $1.1(0.3-3.6)$ \\
\hline $41-50$ & 15 & 3 & 20 & Reference & Reference \\
\hline \multicolumn{6}{|c|}{$\begin{array}{l}\text { Specialized in diagnosis, treatment and } \\
\text { management of infectious diseases }\end{array}$} \\
\hline Yes & 3 & 1 & 33.3 & 0.71 & $1.4(0.2-10.5)$ \\
\hline No & 227 & 52 & 22.9 & Reference & Reference \\
\hline \multicolumn{6}{|l|}{ Education level } \\
\hline Diploma & 144 & 35 & 24.3 & 0.595 & $1.4(0.4-4.5)$ \\
\hline Higher diploma & 13 & 3 & 23.1 & 0.742 & $1.3(0.3-6.5)$ \\
\hline Bachelors & 56 & 12.0 & 21.4 & 0.764 & $1.2(0.3-4.3)$ \\
\hline Postgraduate & 17 & 3 & 17.6 & Reference & Reference \\
\hline \multicolumn{6}{|c|}{ Occupation/ Cadre } \\
\hline Clinical officer & 144 & 34 & 23.6 & 0.378 & $1.6(0.6-4.5)$ \\
\hline Medical officer & 36 & 10 & 27.8 & 0.288 & $1.8(0.6-5.9)$ \\
\hline Dentist & 23 & 5 & 21.7 & 0.568 & $1.4(0.4-5.4)$ \\
\hline Pharmacist & 27 & 4 & 14.8 & Reference & Reference \\
\hline
\end{tabular}

OR - Odd ratio; CI - Confidence Interval; uOR - Unadjusted Odd ratio

Prescription policy guide- institutional antibiograms and the 2016 KEML

A total of $49(21.3 \%)$ had attended training on the rational use of antibiotics within the preceding year. Ten $(4.3 \%)$ were certain they benefitted a lot from the training on antimicrobial resistance patterns while most $(175 ; 76.1 \%)$ of them were not sure (Table III).

Attendance of training on the rational use of antibiotics within the past one year and have benefitted from the training on the changing antimicrobial resistance patterns were not associated with the prescription of antibiotics as per the antibiotic policy guidelines (Table III).

However, when the participants were interviewed on the training aspect of antibiotics-related topics, KII-3 said;

"Trainings are rare here... external continuous medical education and seminars are extremely rare especially on antibiotic topics."

KII-3, Pumwani Maternity Hospital:

“...external trainings can even take years to come by since most are organized by drug or laboratoryequipment companies."

KII-7, Mama Lucy Kibaki Hospital 
Table III: Bivariate analysis of antibiotics training-related factors and antibiotic prescription practice

\begin{tabular}{|c|c|c|c|c|c|}
\hline \multirow{2}{*}{ Variables } & \multirow{3}{*}{$\begin{array}{l}\text { Total } \\
(n=230)\end{array}$} & \multirow{2}{*}{\multicolumn{2}{|c|}{$\begin{array}{l}\text { Prescribed antibiotics as } \\
\text { per the antibiotic policy } \\
\text { guide }\end{array}$}} & \multirow{3}{*}{$P$-value } & \multirow{3}{*}{$\mathrm{uOR}(95 \% \mathrm{CI})$} \\
\hline & & & & & \\
\hline & & $(\mathrm{n}=53)$ & $\%$ & & \\
\hline \multicolumn{6}{|c|}{$\begin{array}{l}\text { Attended at least one training on the rational } \\
\text { use of antibiotics in the past year }\end{array}$} \\
\hline Yes & 49 & 11 & 22.4 & 0.243 & $1.7(0.4-1.2)$ \\
\hline No & 181 & 42 & 23.2 & Reference & Reference \\
\hline \multicolumn{6}{|c|}{$\begin{array}{l}\text { Benefited from a training session on } \\
\text { changing anti-microbial resistance patterns }\end{array}$} \\
\hline A lot & 10 & 2 & 40 & 0.228 & $1.8(0.7-4.5)$ \\
\hline Somehow & 21 & 4 & 19 & 0.366 & $0.7(0.3-1.5)$ \\
\hline Not at all & 24 & 6 & 16.7 & 0.991 & ND \\
\hline Not sure & 175 & 41 & 23.6 & Reference & Reference \\
\hline \multicolumn{6}{|c|}{$\begin{array}{l}\text { Patients insist on antibiotic prescription even } \\
\text { when the disease might not be bacterial? }\end{array}$} \\
\hline Yes & 203 & 45 & 22.2 & 0.45 & $0.7(0.4-1.6)$ \\
\hline No & 27 & 8 & 29.6 & Reference & Reference \\
\hline \multicolumn{6}{|c|}{$\begin{array}{l}\text { Patient satisfaction with the explanation that } \\
\text { antibiotic prescription was not needed }\end{array}$} \\
\hline Satisfied & 44 & 10 & 22.7 & 0.708 & $1.2(0.4-3.5)$ \\
\hline Unsatisfied & 159 & 38 & 23.9 & 0.592 & $1.2(0.5-3.3)$ \\
\hline Still prescribed an antibiotic anyway & 27 & 5 & 18.5 & Reference & Reference \\
\hline
\end{tabular}

OR - Odd ratio; CI - Confidence Interval; $u$ - Unadjusted Odd ratio; ND - Not Computed

Prescription policy guide- Institutional antibiograms and the 2016 KEML

All the prescribers interviewed asserted that continuous training was essential due to the ever-changing patterns of bacterial resistance. Prescribing healthcare workers pointed out that when bacterial strains become resistant, prescribers need to be a step ahead on the prescribing patterns and thus, should be equipped with up-to-date information on bacterial resistance and surveillance data.

When the participants were probed regarding the patients' satisfaction with the explanation that an antibiotic was not needed, majority of the prescribing healthcare workers (159; $69.2 \%)$ stated that the patients were not satisfied while $(44 ; 19.1 \%)$ stated that the patients were satisfied but $11.7 \%$ stated that the patients were unsatisfied upon withholding an antibiotic prescription, yet the healthcare workers still prescribed an antibiotic anyway (Figure 1). The insistence by the patients on specific prescriptions and their satisfaction levels in the absence of antibiotics in their prescriptions did not influence the prescription of antibiotics as per the antibiotic policy guide (Table III). Participants within the Focus Group Discussion (FGDs) gave mixed responses in regard to antibiotic prescriptions among the healthcare workers. 


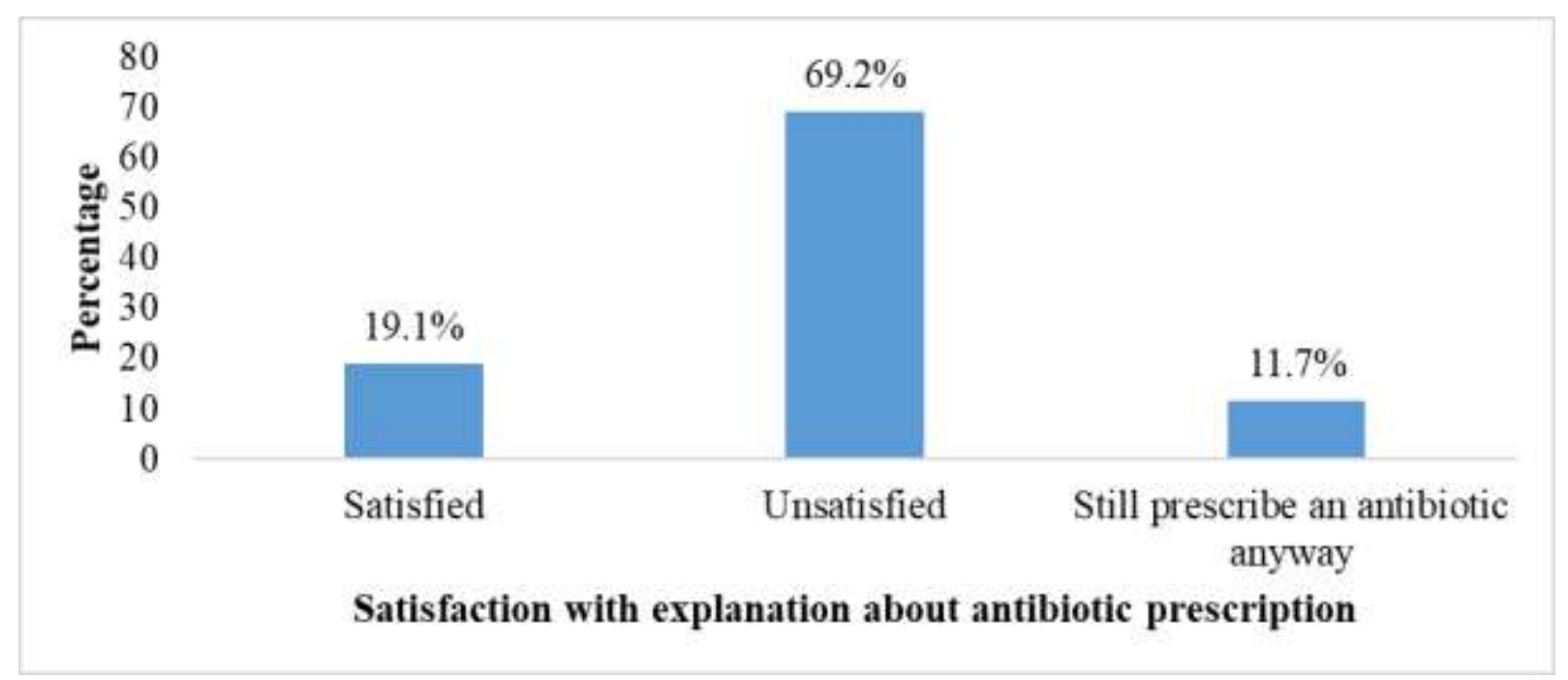

Figure 1: Patient's satisfaction with the explanation that an antibiotic was not needed

A participant from FDG-4 from Pumwani Maternity Hospital stated:

"I will want a clinician who will prescribe an antibiotic that will treat all infections and so most time I go to the doctor, either for me or my baby, I remind them not to forget an antibiotic."

The themes selected were based on answering the research questions and a majority of the participants in the FGDs reported that antibiotics were important to them and would request clinician's prescription or buy the antibiotics over the counter during refill of other medicines for various illnesses. Concerning what patients do when a clinician withholds an antibiotic prescription, a participant from FDG-1 (Mbagathi Hospital) said:

"I demand an antibiotic prescription and if I am lucky the doctor will add an antibiotic on top of the other prescribed medicines."

When prescribing healthcare workers were interviewed on the same subject, one KII-8
(Mama Lucy Kibaki Hospital) said:

"It surprises me that a patient will come to a hospital with a mentality that every prescription must have an antibiotic in it and some will even ask me which antibiotic I have prescribed."

Use of the 2016 KEML guideline to guide antibiotic prescription

With regards to prescribing antibiotics according to the 2016 Kenya Essential Medical List (KEML), only 12 (5.2\%) stated they always referred to this guideline, $98(42.6 \%)$ stated they sometimes referred to the guidelines, 80 $(34.8 \%)$ rarely did while $40(17.4 \%)$ never referred to this guideline (Table IV).

Knowledge and practice-related factors associated with antibiotic prescription

Prescribers who reported that oral antibiotics were commonly misused ( $\mathrm{OR}=0.4,95 \% \mathrm{CI}$ $0.2-0.9)$ were less likely to prescribe antibiotics in accordance to antibiotic policy guidelines compared to those who reported topical antibiotics as the most commonly misused (Table IV) form. 
Table IV: Bivariate analysis of knowledge and practice-related factors and antibiotic prescription

\begin{tabular}{|c|c|c|c|c|c|}
\hline \multirow[t]{2}{*}{ Variables } & \multirow{2}{*}{$\begin{array}{l}\text { Total } \\
(n=230)\end{array}$} & \multicolumn{2}{|c|}{$\begin{array}{l}\text { Prescribed antibiotics as } \\
\text { per the antibiotic policy }\end{array}$} & \multirow[t]{2}{*}{$P$-value } & \multirow[t]{2}{*}{ uOR $(95 \% \mathrm{CI})$} \\
\hline & & $(\mathrm{n}=53)$ & $\%$ & & \\
\hline \multicolumn{6}{|c|}{ Antibiotics have for long been misused? } \\
\hline Yes & 227 & 50 & 22 & 0.243 & $0.7(0.4-1.2)$ \\
\hline No & 3 & 3 & 100 & Reference & Reference \\
\hline \multicolumn{6}{|c|}{ Types of antibiotics misused } \\
\hline Oral & 148 & 28 & 18.9 & 0.021 & $0.4(0.2-0.9)$ \\
\hline Injectable & 68 & 18 & 26.5 & 0.153 & $0.5(0.2-1.2)$ \\
\hline Topical & 14 & 7 & 50 & Reference & Reference \\
\hline \multicolumn{6}{|c|}{$\begin{array}{l}\text { Does the institution have an antibiotic } \\
\text { prescribing policy? }\end{array}$} \\
\hline Yes & 100 & 50 & 50 & 0.001 & $25(6.1-102.7)$ \\
\hline No & 30 & 1 & 3.3 & 0.677 & $1.7(0.2-18.3)$ \\
\hline Not sure & 100 & 2 & 2 & Reference & Reference \\
\hline \multicolumn{6}{|c|}{$\begin{array}{l}\text { Refers to the } 2016 \text { KEML guideline to } \\
\text { prescribe antibiotics? }\end{array}$} \\
\hline Always & 12 & 10 & 83.3 & 0.001 & $5.6(2.1-15.3)$ \\
\hline Sometimes & 98 & 22 & 22.4 & 0.381 & $1.4(0.6-3.7)$ \\
\hline Rarely & 80 & 15.0 & 18.8 & 0.644 & $1.3(0.5-3.2)$ \\
\hline Never & 40 & 6.0 & 15 & Reference & Reference \\
\hline \multicolumn{6}{|c|}{ Does the institution have an antibiogram? } \\
\hline Yes & 98 & 20 & 20.4 & 0.52 & $0.8(0.4-1.6)$ \\
\hline No & 73 & 18 & 24.7 & 0.93 & $0.9(0.5-1.9)$ \\
\hline Not sure & 59 & 15 & 25.4 & Reference & Reference \\
\hline \multicolumn{6}{|c|}{$\begin{array}{l}\text { Separate antibiograms for inpatients and } \\
\text { outpatients? }\end{array}$} \\
\hline Yes & 2 & 2 & 100 & 0.044 & $4.4(1.04-18.5)$ \\
\hline No & 26 & 4 & 15.4 & 0.469 & $0.7(0.2-1.9)$ \\
\hline Not sure & 202 & 47 & 23.3 & Reference & Reference \\
\hline
\end{tabular}

OR - Odd ratio; CI - Confidence Interval; u - Unadjusted Odd ratio

Prescription policy guide- Institutional antibiograms and the 2016 KEML

Prescribing healthcare workers who always referred to the 2016 KEML during the prescription of antibiotics (OR=5.6, 95\% CI 2.115.3) were more likely to prescribe as per the antibiotic prescription guidelines compared to prescribing healthcare workers who never referred to the policy. Prescribing healthcare workers with the knowledge of the presence of separate antibiograms for inpatient and outpatient departments $(\mathrm{OR}=4.4,95 \% \mathrm{CI}$
(1.04-18.5) were more likely to prescribe antibiotics as per the given policy compared to prescribers who were not sure of the separate antibiograms (Table IV).

After adjusting for confounders, oral antibiotics (OR $=0.5,95 \% \mathrm{CI} 0.3-0.9)$, always referring to the 2016 KEML before prescribing antibiotics $(\mathrm{OR}=4.2,95 \%$ CI 1.3-13.1), separating antibiograms for inpatient and outpatient departments (OR $=4.395 \%$ CI 1.11- 
15.5), and confidence level among prescribing healthcare workers to prescribe antibiotics without laboratory tests $(\mathrm{OR}=0.3,95 \% \mathrm{CI} 0.2$ -
$0.8)$ were associated with the prescription of antibiotics as per the policy (Table V).

Table V: Multivariate analysis of factors associated with an antibiotic prescription

\begin{tabular}{|c|c|c|c|c|c|}
\hline \multirow{2}{*}{ Variables } & \multirow[b]{2}{*}{$\begin{array}{l}\text { Total } \\
(n=230)\end{array}$} & \multirow{2}{*}{\multicolumn{2}{|c|}{$\begin{array}{l}\text { Prescribe antibiotics as } \\
\text { per the antibiotic policy } \\
\text { guide }\end{array}$}} & \multirow{3}{*}{$P$-value } & \multirow{3}{*}{ aOR $(95 \% \mathrm{CI})$} \\
\hline & & & & & \\
\hline & & $(\mathrm{n}=53)$ & $\%$ & & \\
\hline \multicolumn{6}{|c|}{ Types of antibiotics misused } \\
\hline Oral & 148 & 28 & 18.9 & 0.036 & $0.5(0.3-0.9)$ \\
\hline Injectable & 68 & 18 & 26.5 & 0.153 & $0.5(0.2-1.2)$ \\
\hline Topical & 14 & 7 & 50 & Reference & Reference \\
\hline \multicolumn{6}{|c|}{ Refers to the 2016 Kenya Essential Medicines } \\
\hline Always & 12 & 10 & 83.3 & 0.012 & $4.2(1.3-13.1)$ \\
\hline Sometimes & 98 & 22 & 22.4 & 0.381 & $1.4(0.6-3.7)$ \\
\hline Rarely & 80 & 15.0 & 18.8 & 0.644 & $1.3(0.5-3.2)$ \\
\hline Never & 40 & 6.0 & 15 & Reference & Reference \\
\hline \multicolumn{6}{|c|}{$\begin{array}{l}\text { Separate antibiograms for inpatients and } \\
\text { outpatients? }\end{array}$} \\
\hline Yes & 2 & 2 & 100 & 0.048 & $4.3(1.11-15.5)$ \\
\hline No & 26 & 4 & 15.4 & 0.469 & $0.7(0.2-1.9)$ \\
\hline Not sure & 202 & 47 & 23.3 & Reference & Reference \\
\hline \multicolumn{6}{|c|}{$\begin{array}{l}\text { Confidence levels of antibiotics prescription } \\
\text { without laboratory tests }\end{array}$} \\
\hline Not confident & 2 & 0 & 0 & 0.988 & ND \\
\hline Moderately confident & 216 & 47 & 21.8 & 0.039 & $0.3(0.2-0.8)$ \\
\hline Completely confident & 12 & 6 & 50 & Reference & Reference \\
\hline
\end{tabular}

OR - Odd ratio; CI - confidence interval; a - adjusted OR (significant variables); ND - Not computed

Prescription policy guide -Institutional antibiograms and the 2016 KEML

\section{Discussion}

Based on the delivery mode, whether oral, topical, by injection and or by a combination of routes, antibiotics were prescribed differently in terms of frequencies among the prescribing healthcare workers in this study. In addition, most study respondents (98.7\%) indicated that antibiotics have for long been wrongly prescribed, especially the orally administered ones. This is similar to the findings of a study done in Kenya that showed orally administered antibiotics were predominantly prescribed especially among outpatients. [12] Factors associated with this observation may be the ease of administering an oral antibiotic, availability of the antibiotic, disease severity and cost implications. Moreover, administering injectable antibiotics require some expertise, most likely from a healthcare provider and in most instances, may require hospitalization. Oral antibiotics, 
on the other hand, can be self-administered following the instructions given to them by the pharmacist.

Relatively few prescribing healthcare workers adhered to the Kenya Essential Medicines List $(5.2 \%)$ or the institutional policy guidelines $(23 \%)$ to prescribe antibiotics despite the majority of prescribing healthcare workers stating that antibiotic misuse is a leading cause of bacterial resistance. This echoes the observations reported in a study that reported the majority of physicians were well informed on the problems of antibiotic resistance, yet more than half prescribed antibiotics inappropriately in their institutions. [13] The revised KEML mirrors the WHO Essential Drugs List which has previously been reported to greatly influence prescribers and promote rational use of antibiotics for patients` best clinical outcomes. ${ }^{[14]}$ Prescribing healthcare workers who referred to antibiotic prescription policy guide were more likely to prescribe according to the guidelines compared to healthcare workers who never referred to the policy guide. From the KIIs, it was worth noting that some specialists would prescribe some antibiotics outside the recommendations of the KEML, depending on patients' infection state and laboratory test guides. Nonetheless, restriction policy on antibiotic prescription has been shown to promote their rational use but adherence to the policy is influenced by numerous challenges such as poor dissemination of the guidelines and inadequate training on the ever-changing patterns of bacterial resistance. [15] Effective educational and managerial interventions can improve antibiotic use by $20 \%-30 \%$. [16] While the majority of the participants in the present study were junior cadre health practitioners with non-degree qualifications, previous studies in Kenya and Nigeria have demonstrated that this group of prescribing healthcare workers generates more prescriptions than senior healthcare practitioners such as doctors and specialists. [9] [17] In the Kenyan public health setting, clinical officers are the primary healthcare providers and are the first medical practitioners to evaluate and review patients at the outpatient departments hence, they are more likely to initiate an antibiotic prescription.

The roles played by the various specialists greatly influence antibiotic prescription; their presence and input have been associated with appropriate antibiotic prescription practices. [18] Only $1.3 \%$ of the prescribing healthcare workers in the present study had specialized in the field of infectious diseases. From other studies, the continuous consultation and advice from infectious disease specialists (IDS) have been demonstrated as a key intervention component for optimal use of antibiotics. ${ }^{[19]} \mathrm{A}$ study involving data from 170 hospitals in 32 countries investigated the role played by IDS/Microbiologists and pharmacists and found that $41 \%$ of IDS and $16 \%$ of pharmacists visited the wards daily and their presence and input was associated with good monitoring of laboratory culture results and antibiograms guide for an empirical antibiotic prescription. [20] Specialists can be utilized to train junior prescribers and continuous updates on the changing patterns of bacterial resistance. Prescribing patterns is key to the rational use of antibiotics. Ironically, close to $80 \%$ of prescribing healthcare workers in the present study stated that they had not attended any training on the rational use of antibiotics within the preceding year and even for those who had attended, most felt that they were not sure that the training was beneficial to their daily practice. These observations correspond to previous findings that non-trained prescribers generate more antibiotic prescriptions. [19] For instance, even though $95 \%$ of junior doctors perceived antibiotic resistance as a national problem in France and Scotland, only $31 \%$ of the doctors could give the correct prevalence of antibiotic misuse in their countries. [21] When prescribing healthcare workers are well informed, they educate patients and families on the 
appropriateness of antibiotic use. [12]

Laboratory investigations confirm the diagnoses made by healthcare workers and boost their confidence in the act of prescribing. From the findings in the present study, healthcare workers who prescribed antibiotics without relevant laboratory investigations were less likely to be confident to prescribe antibiotics as per the antibiotic prescription policy guidelines. Laboratory microbial data generated from isolation and antimicrobial sensitivity tests are necessary for the current development of antibiograms. In lowresourced African countries, antibiograms are essential to guide healthcare workers while prescribing antibiotics. This promotes rational use of antibiotics hence minimizing the tendency for bacterial resistance. Compilation of laboratory microbial and sensitivity data is essential as it enables the region-specific formulation of antibiograms. From the findings in the present study, more than half of the healthcare workers were unaware of the availability of antibiograms and those who were aware were more likely to prescribe as per the given policy guideline. However, less than $1 \%$ of the participants had knowledge of separate antibiograms for inpatient and outpatient departments. The findings are similar to that of an Indian survey that reported less than $10 \%$ of the prescribers used antibiograms to guide treatment. [22] Physicians (93\% of total) cited having challenges while selecting appropriate antibiotic in a different study. [13] Updated antibiograms are best suited to remedy the challenge of antibiotic selection based on the changing patterns of region-specific bacterial resistance, especially in low-resourced areas where laboratory infrastructure may be poor or underequipped.

This study is limited by the fact that only antibiotic prescription practices among prescribing healthcare workers were studied. It was beyond the scope of this study to assess the prescription of other medications.

\section{Conclusion}

The high antibiotic prescription rate among healthcare workers was influenced by the types of antibiotics, the prescriber's reference to the Kenya Essential Medicines List (KEML), laboratory results utilization to guide prescriptions and knowledge and awareness of separate antibiograms between inpatient and outpatient departments in public hospitals in Nairobi County. The study recommends that the use of antibiotic prescribing guide among healthcare workers is a good practice to promote the rational use of antibiotics and reduce bacterial resistance.

Acknowledgements: Special thanks to the staff of Kenyatta National Hospital, Mbagathi Hospital, Mama Lucy Kibaki Hospital and Pumwani Maternity Hospital for providing technical assistance during the study. The authors also show gratitude to all the study participants and research assistants for their cooperation.

Authors' contributions: MOW participated in the conception and design, data collection, data analysis and drafting of the manuscript. ENE and OSO participated in the study design, data collection and data analysis. MMW participated in data collection. All the authors approved the final version of the manuscript.

Conflict of Interests: None.

Funding: Self-funded.

Publication History: Submitted 28 October 2019; Accepted 01 February 2020.

\section{References}

1. World Health Organization. Essential medicines and health products: The Pursuit of Responsible Use of Medicines: Sharing and Learning from Country Experiences 2017. Available at: http://www.who.int/medicines/areas/ra tional_use/en/ Accessed in October 2018.

2. Means AR, Weaver MR, Burnett SM, Mbonye MK, Naikoba S, McClelland RS. Correlates of inappropriate prescribing of 
antibiotics to patients with malaria in Uganda. PLoS ONE 2014; 9: e90179.

3. Isah A, Ross-Degnan D, Quick J, Laing R, Mabadeje A. The development of standard values for the WHO drug use prescribing indicators. International Conferences on Improving Use of Medicines 2014; 1-6.

4. Ofori-Asenso R, Brhlikova P, Pollock AM. Prescribing indicators at primary health care centers within the WHO African region: a systematic analysis (1995-2015). BMC Public Health 2016; 16: 724.

5. Risk R, Naismith H, Burnett A, Moore SE, Cham M, Unger S. Rational prescribing in paediatrics in a resource-limited setting. Arch Dis Child 2013; 98: 503-509.

6. Gulliford MC, Dregan A, Moore MV, Ashworth M, Staa T, McCann G, et al. Continued high rates of antibiotic prescribing to adults with respiratory tract infection: a survey of 568 UK general practices. BMJ Open 2014; 4: e006245.

7. Braykov NP, Morgan DJ, Schweizer ML, Uslan DZ, Kelesidis T, Weisenberg SA, et al. Assessment of empirical antibiotic therapy optimisation in six hospitals: An observational cohort study. The Lancet Infect Dis 2014; 14: 1220-1227.

8. World Health Organization. WHO's first global report on antibiotic resistance reveals serious, worldwide threat to public health. World Health Organization 2014. Available at https://www.who.int/mediacentre/news /releases/2014/amr-report/en/ Accessed on $13^{\text {th }}$ August 2018.

9. Mulwa NC, Osanjo GO, Ndwigah SN, Kaburi AN, Muriuki G. Patterns of Prescribing Practices in Makueni County Referral Hospital, Kenya. Afr J Pharmacol Therap 2015; 4: 161-168.

10. Nairobi County Government. Nairobi City County, Pumwani Maternity Hospital. 2019. Available

at https://nairobi.go.ke/pumwanimaternity-hospital/.
11. Daniel W. Biostatistics: A Foundation for Analysis in the Health Sciences (7th edition). Technometrics. John Wiley \& Sons. 1999..

12. Sanchez GV, Fleming-Dutra KE, Roberts RM, Hicks LA. Core Elements of Outpatient Antibiotic Stewardship. Morbidity and Mortality Weekly Report. Recommendations and Reports 2016: 65; $1-12$.

13. Om C, Vlieghe E, McLaughlin JC, Daily F, McLaws ML. Antibiotic prescribing practices: A national survey of Cambodian physicians. Am J Infect Control 2016; 44: 1144-1148.

14. Ntšekhe $M$ and Tjipura D. Antibiotic Prescribing Patterns at Six Hospitals in Lesotho. Submitted to the US Agency for International Development by the Strengthening Pharmaceutical Systems (SPS) Program. Arlington, VA: Management Sciences for Health. Strengthening 2011; 1-40

15. Tunger O, Karakaya Y, Cetin CB, Dinc G, Borand H. Rational antibiotic use. J Infect Developing Ctries 2009; 3: 88-93.

16. Holloway KA. Promoting the rational use of antibiotics. Regional Health Forum 2011; 15: 122-130.

17. Babalola CPI, Awoleye SA, Akinyemi JO, Olayinka K. Evaluation of prescription pattern in Osun State (Southwest) Nigeria. J Public Health Epidemiol 2001; 3: 94-98.

18. Pulcini C, Botelho-Nevers E, Dyar OJ, Harbarth S. The impact of infectious disease specialists on antibiotic prescribing in hospitals. Clin Microbiol Infect 2014; 20: 963-972.

19. Wang KY, Seed P, Schofield P, Ibrahim S, Ashworth $\mathrm{M}$. Which practices are high antibiotic prescribers? A cross-sectional analysis. Brit J Gen Pract 2009; 59: 724-727.

20. MacKenzie FM, Gould IM, Bruce J, Mollison J, Monnet DL, Krcmery V, et al. 
The role of microbiology and pharmacy departments in the stewardship of antibiotic prescribing in European hospitals. J Hosp Infect 2007; 65: 73-81.

21. Pulcini C, Williams F, Molinari N, Davey $P$, Nathwani D. Junior doctors' knowledge and perceptions of antibiotic resistance and prescribing: A survey in France and Scotland. Clin Microbiol Infect 2011; 17:

22. Sivagnanam

Thirumalaikolundusubramanian

G,

Mohanasundaram J, Raaj AA, Namasivayam KRS. A survey on current attitude of practising physicians upon usage of antimicrobial agents in southern part of India. MedGenMed: Medscape Gen Med 2004; 6: 1 . 80-87. 